\title{
Preliminary Evaluation of Outcomes of Transactional Analysis Psychotherapy for Armed Forces Veterans presenting with Post-Traumatic Stress Disorder
}

\section{(C) 2013 David Harford}

\begin{abstract}
This brief outline presents some initial findings from a pilot project conducted within a charity setting in the UK, examining clinical outcomes for a cohort of armed forces veterans presenting with post-traumatic stress disorder (PTSD). Outcomes were measured using CORE-OM (Evans et al 2000), PHQ-9 (Kroenke et al 2001) and GAD-7 (Spitzer et al 2006). Preliminary findings show that positive Reliable Change on global distress and anxiety had taken place within 16 sessions. These results suggest that transactional analysis psychotherapy has promise for treatment of PTSD with this client group and that further research is warranted.
\end{abstract}

Key words

Post-Traumatic Stress Disorder, PTSD, CORE-OM, PHQ-9, GAD-7, Armed Forces Veterans, Transactional Analysis Psychotherapy

\section{Introduction}

The working hypothesis chosen for this pilot project was that 'transactional analysis psychotherapy is an effective treatment for post-traumatic stress disorder (PTSD)'. At the time of writing, there is no published research investigating the effectiveness of TA psychotherapy in the treatment of PTSD, nor is there any written record of CORE-OM, PHQ-9 and GAD-7 questionnaires being employed in the provision of TA psychotherapy in this clinical context and with this client group. Guidelines issued by the UK National Institute for Clinical Excellence (NICE 2005) state that 'there is as yet no convincing evidence for a clinically important effect of (other therapies) on PTSD (p.19) and instead, recommends "a course of trauma-focused psychological treatment, trauma-focused cognitive behavioural therapy [CBT] or eye movement desensitisation and reprocessing [EMDR])" (p.4). There is, therefore, a strong case for building the evidence base for TA psychotherapy in the treatment of PTSD and, thereby, influencing health policy and strategy within the UK
National Health Service (NHS) and at local and national government levels.

The motivation for the pilot project was the author's identification of this clear gap in the available research literature, coupled with an awareness that it is highly unusual for a private practitioner to be afforded the opportunity of providing long-term TA psychotherapy on an indefinite basis with no limit on the number of sessions available for each client. In addition, there has been intense media coverage of the problems faced by military personnel returning from Afghanistan and Iraq in recent years, which has brought the need for a broader range of effective treatments for PTSD sharply into focus.

\section{Method}

\section{Participants}

The participants were six male armed forces veterans, all of whom had been formally diagnosed with PTSD deriving from various traumatic experiences encountered while serving in the armed forces. Participants were referred for psychotherapy by the independent charity providing their accommodation, care and support. The therapy was conducted as part of a pilot project using a naturalistic protocol within a room provided by the charity within their premises. All six participants were aware that their questionnaire responses would be collected and used for both fundraising and research purposes and gave their full written consent for this process.

\section{Therapy}

The form of TA psychotherapy chosen was primarily the integrative model advanced by Erskine (1993) and Erskine and Trautmann (1996), with an emphasis on facilitating internal contact (Erskine, 1993) with previously repressed affect, providing an attuned response to that affect and strengthening veterans' Integrating Adult (Tudor, 2003) capacity "to reflect upon and integrate their own archaic states as well as past introjects, and draw on them in the service of present- 
centred relating" (p.202). This integrative model was augmented by the relational TA approach outlined by Hargaden and Sills (2002), where sustained empathic transactions (Clark, 1991) and strict observance of boundaries were used to provide 'the "safe container [of an attuned therapeutic relationship] in which the [veterans could] begin to integrate" (p.29) their fragmented selves, rediscover lost skills and resources and begin to build a number of mutually beneficial interpersonal relationships and a more rewarding and meaningful life.

\section{Data Collection}

The CORE-OM questionnaire (Evans et al 2000) is a 34item generic measure of psychological distress, which is pan-theoretical and pan-diagnostic and, therefore, readily applied to any TA psychotherapy context as a means of assessing mental well-being before, during and after treatment. This measure is widely used across the NHS and by independent counselling and psychotherapy providers.

Gathered concurrently were multiple-choice answers to the nine-point PHQ-9 Depression Severity (Kroenke et al 2001) and seven-point GAD-7 (Spitzer et al 2006) indicators: again, these are widely used in both NHS and private settings and the latter has been trialled successfully with clients presenting with PTSD.

Responses to CORE-OM, PHQ-9 and GAD-7 were collected from all six veterans at four-weekly intervals from assessment onwards, to measure changes in global distress/functioning, depressive symptoms and anxiety. In addition, a mean figure was calculated for each type of questionnaire. At the time of writing, complete results have been gathered for six veterans for a period of sixteen sessions of individual TA therapy. These are shown in Figure 1.

\section{Results}

Pre-treatment levels of symptoms among all six veterans were in the clinical range of severity. The results gathered during ongoing treatment appeared to correspond with prior expectations that some emotional "turbulence [would] occur as part of the change process" (Widdowson 2010 p.203); more specifically, that veterans would feel somewhat worse before they began to improve as they made internal contact (Erskine, 1993) with previously repressed affect, leading to a temporary intensification of their distress.

The results for the CORE-OM and GAD-7 questionnaires demonstrate Reliable Change over the sixteen sessions, but not quite at the level of Clinically Significant Change. In other words, the veterans' overall mental well-being has improved significantly over the course of TA treatment to an extent beyond that which could be accounted for by non-clinical factors, such as measurement error - but not yet to the extent that their symptoms have reduced to levels found within the socalled "normal" wider population.

Figure 1: Mean CORE-OM, PHQ-9 and GAD-7

Scores for 6 clients

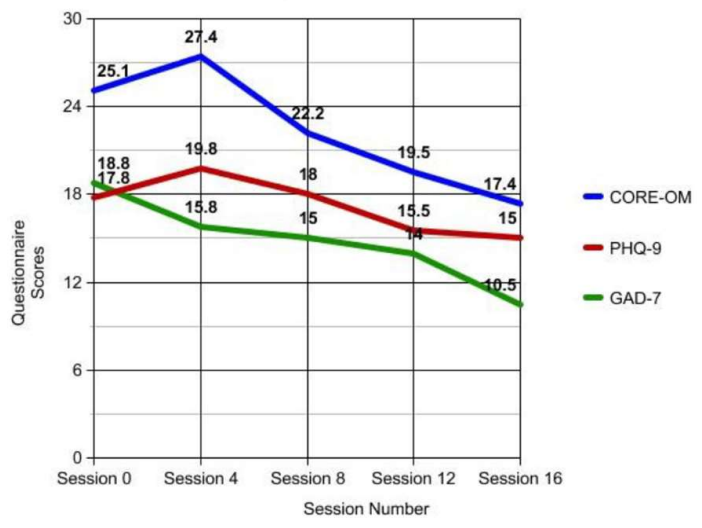

\section{Discussion}

These pilot project findings offer an encouraging level of support for the working hypothesis that 'TA psychotherapy is an effective treatment for PTSD' and suggest that further research investigating the process and outcome of therapy for PTSD is warranted. However, it must be noted that these are only preliminary results from the pilot project and that a more extensive programme of data collection is underway with a larger cohort of veterans employing a wider array of statistical measures and additional tools. Based on the results gathered so far, in this pilot project both anxiety and, to a lesser extent, depression appear to gradually reduce as, within the non-intrusive safety of an empathic therapeutic relationship, the veterans re-experience previously repressed affect, obtain the longed-for attuned response to their pain and then slowly build their Integrating Adult to reflect upon and integrate archaic states and introjects, and draw on them for presentcentred relating (as quoted above Tudor 2003).

The use of CORE-OM, PHQ-9 and GAD-7 questionnaires with this challenging client group has proved a useful addition to established TA psychotherapy practice.

Prior to commencing this research, there were concerns that such methods might present a counter-therapeutic intrusion of bureaucracy into fragile therapeutic alliances. Carefully contracted use of questionnaires appears, instead, to have gone some way to satisfying veterans' structure-hunger (Berne, 1961) in the face of self-fragmentation, provided "a degree of emotional containment" (Widdowson 2010 p.203) and afforded a way for these vulnerable clients to measure and conceptualise their labile phenomenological experience.

Furthermore, this approach has included the veterans fully in the unfolding process of their therapy, which is 
congruent with Berne's $(1961,1966)$ inclusive treatment ethos.

David Harford is a Certified Transactional Analyst (Psychotherapy) and can be contacted on harfordtherapy@gmail.com.

\section{References}

Berne, E (1961) Transactional Analysis in Psychotherapy New York: Grove Press

Berne, E. (1966) Principles of Group Treatment, New York: Oxford University Press

Clark, B. D. (1991). Empathic transactions in the deconfusion of child ego states. Transactional Analysis Journal, 21 92-98.

Erskine, R.G. (1993) Inquiry, attunement and involvement in the psychotherapy of dissociation. Transactional Analysis Journal, 23: 4 185-190

Erskine, R \& Trautmann, R (1996) The Process of Integrative Psychotherapy Transactional Analysis Journal 26: 4 316-328
Evans, C, Mellor-Clark, J, Margison, F, Barkham, M, McGrath, G, Connell, J, Audin, K. (2000), 'Clinical Outcomes in Routine Evaluation: The CORE-OM', Journal of Mental Health: 9, p.247255

Hargaden, H \& Sills C (2002) Transactional Analysis - A Relational Perspective Hove: Brunner-Routledge

Kroenke, K, Spitzer, R, Williams J. (2001), 'The PHQ-9: Validity of a Brief Depression Severity Measure', Journal of General Internal Medicine: 16, p.606-613

National Institute for Clinical Excellence (2005), 'CG26 - Posttraumatic stress disorder (PTSD): The management of PTSD in adults and children in primary and secondary care' http://www.nice.org.uk/cg26 accessed 1 July 2013

Spitzer, R, Kroenke, K, Williams J, Löwe B. (2006), 'A Brief Measure for Assessing Generalized Anxiety Disorder: The GAD-7', Archives of Internal Medicine 166, p.1092-1097

Tudor, K (2003) The Neopsyche: The integrating adult ego state. In C. Sills \& H Hargaden (eds) Ego states. London: Worth Publishing $201-231$

Widdowson, M. (2010), Transactional Analysis: 100 Key Points \& Techniques London: Routledge 